\title{
Analysis of hurling and camogie injuries
}

\author{
P.J. Crowley ${ }^{1}$, MBDCh and K.C. Condon ${ }^{2}$, FRCSI
}

${ }^{1}$ General Practitioner, Ovens, Co. Cork, Eire

${ }^{2}$ Consultant Plastic Surgeon, Cork Regional Hospital, Wilton, Cork, Eire

In 1984, 4500 people with sport injuries attended the Cork Regional Hospital. Of these, 817 were injured in the national game of hurling and camogie. Hand injuries were the most frequent occurring in approximately one third of injured players ( 33 per cent) and of these, just half had a closed metacarpal fracture. Facial injuries were the second most frequent category ( 28 per cent). Almost one third of these were nasal fractures, while forehead and eyebrow lacerations, fractured zygoma, loss of teeth are also common.

Sport eye injuries referred to the Eye, Ear and Throat Hospital in Cork during the same period amounted to 107, of which 26 occurred in hurling.

It is believed that a properly designed protective head gear would largely eliminate such facial and eye injuries.

Keywords: Hurling, camogie, injuries

\section{Introduction}

The origin of the game hurling or camogie is lost in Irish folklore and legend. The Gaelic Athletic Association has, since 1884, laid down that it is a team game of 15 players a side and 70 minutes per game. The object is to drive a small hard leather ball between two posts shaped like a capital $\mathrm{H}$. The ball weighs approximately $100 \mathrm{~g}$ and is controlled and moved by a broad-bladed stick known as a hurley.

The hurley is made of ash, a hard spring wood and is one metre in length and $600 \mathrm{~g}$ in weight. The blade resembles a wide heavy two-sided hockey stick. The moving ball is frequently struck high in the air while in motion (Figure 1). An expert may propel the ball, which is leather and resembles a small cricket ball with raised ridges, for 80 to $90 \mathrm{~m}$. There is close contact between players in a fast skilful game. Protective head gear or other protective clothing such as gloves are as yet not usually worn. The female equivalent of this game is known as camogie.

\section{Material and methods}

Cork city and county is a major centre of hurling and the accident centre at the Cork Regional Hospital provides the major accident and emergency services of the whole region (Figure 2).

The vast majority of sport injuries requiring hospitalization are dealt with in this centre. The following

Address for correspondence: Dr P.J. Crowley

(C) 1989 Butterworth \& Co (Publishers) Ltd 0306-3674/89/030183-03 \$03.00

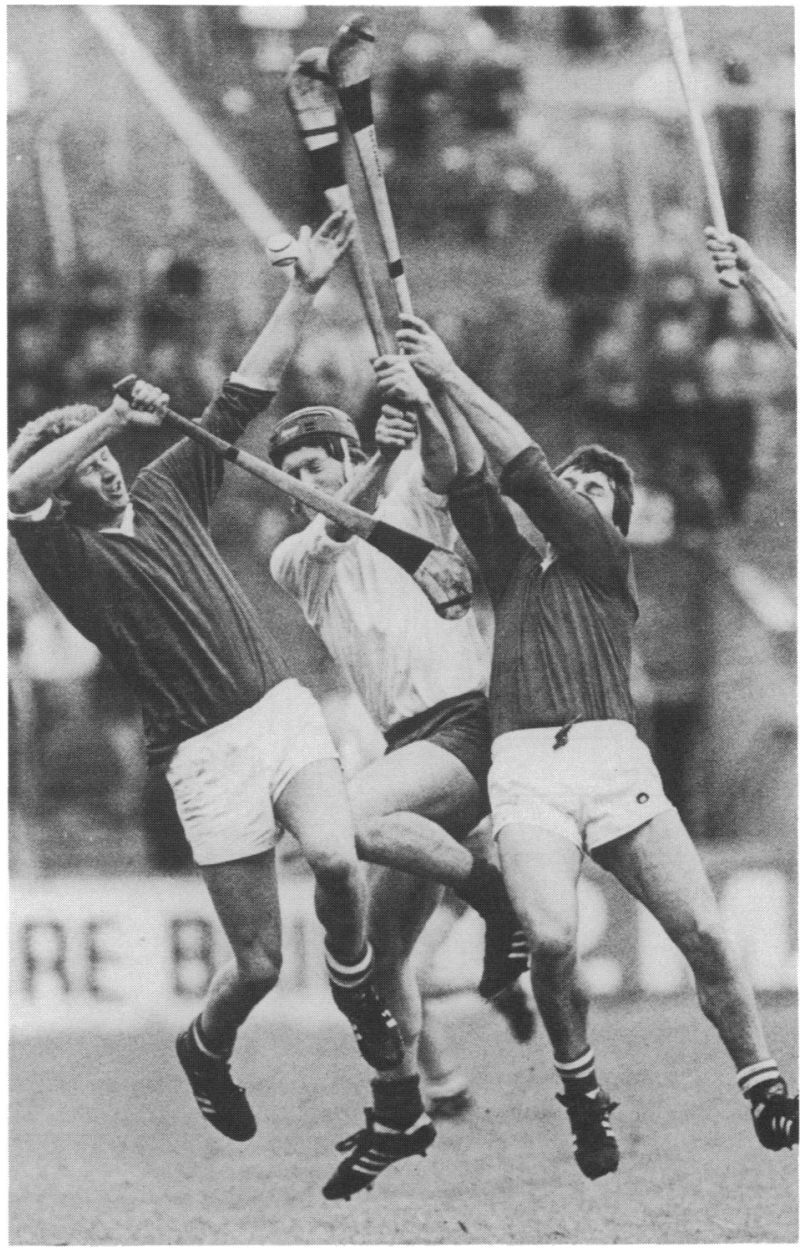

Figure 1. Action shot from a hurling game.

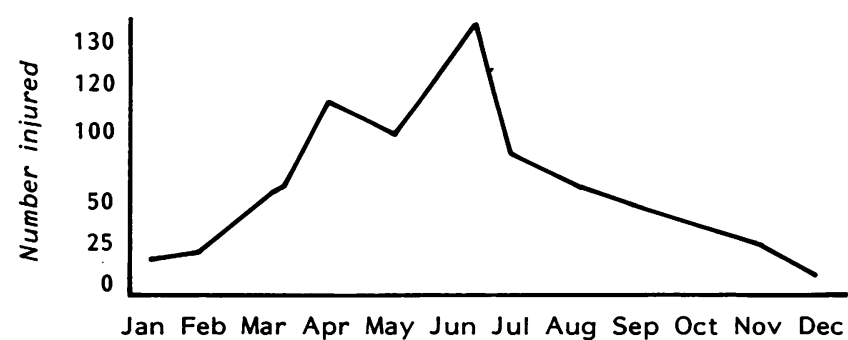

Figure 2. Number of patients who attended Cork Regional Hospital each month 


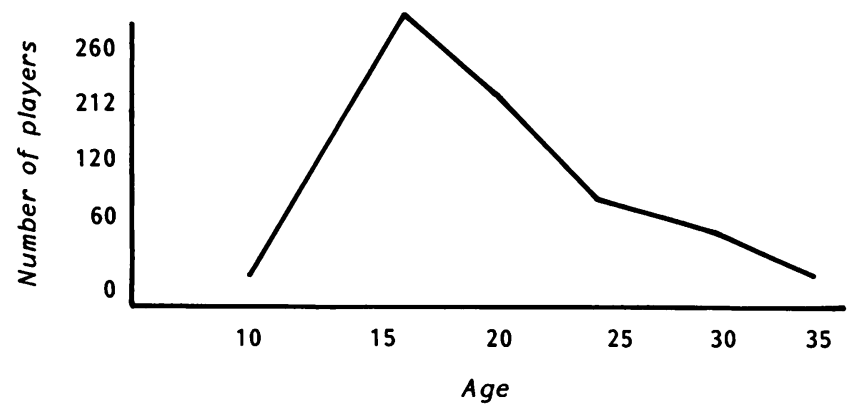

Figure 3. Age distribution

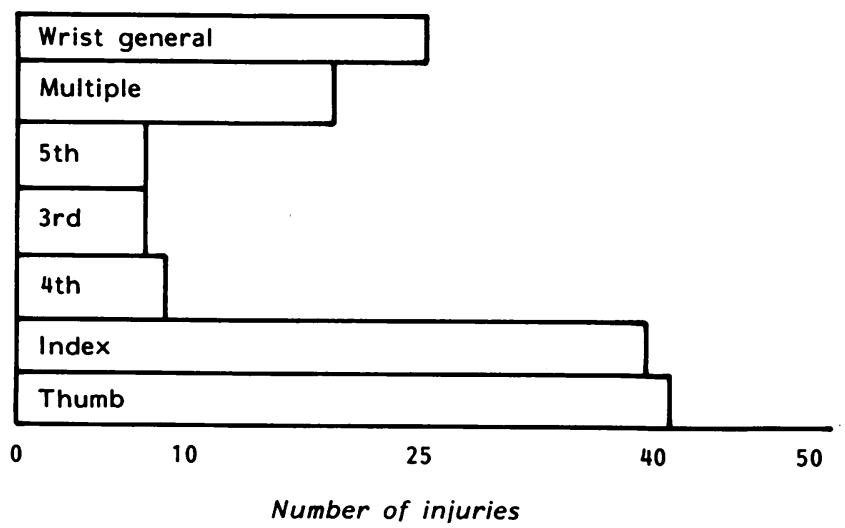

Figure 4. Hand injuries

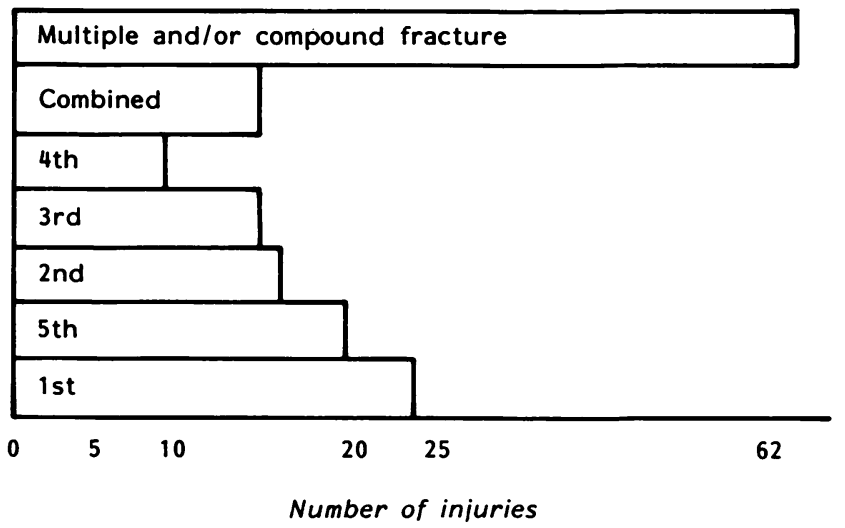

Figure 5. Metacarpal injuries

items of information were recorded for each player in 1984:

Month (Jan-Dec)

Game (hurling or camogie)

Year of birth

Side of injury (left or right)

Main site of injury

Sub-site(s) within main site of injury

Nature of injury (fracture, laceration, etc.)

X-ray result (where applicable).

The average age of the players injured from hurling was $21.0 \mathrm{yr}$ (std $\mathrm{dev}=6.7 \mathrm{yr}$ ) and $17.9 \mathrm{yr}$ (std $\mathrm{dev}+5.7 \mathrm{yr}$ ) for camogie players (Figure 3 ). Hand injuries occurred in 297 ( 36 per cent) of players (Figures 4 and 5). The second most common injury was to the face, and combined face and head injuries accounted for 28 per cent of all injuries (Figure 6). The injury sites are outlined in Figure 7 . There was no evidence in the

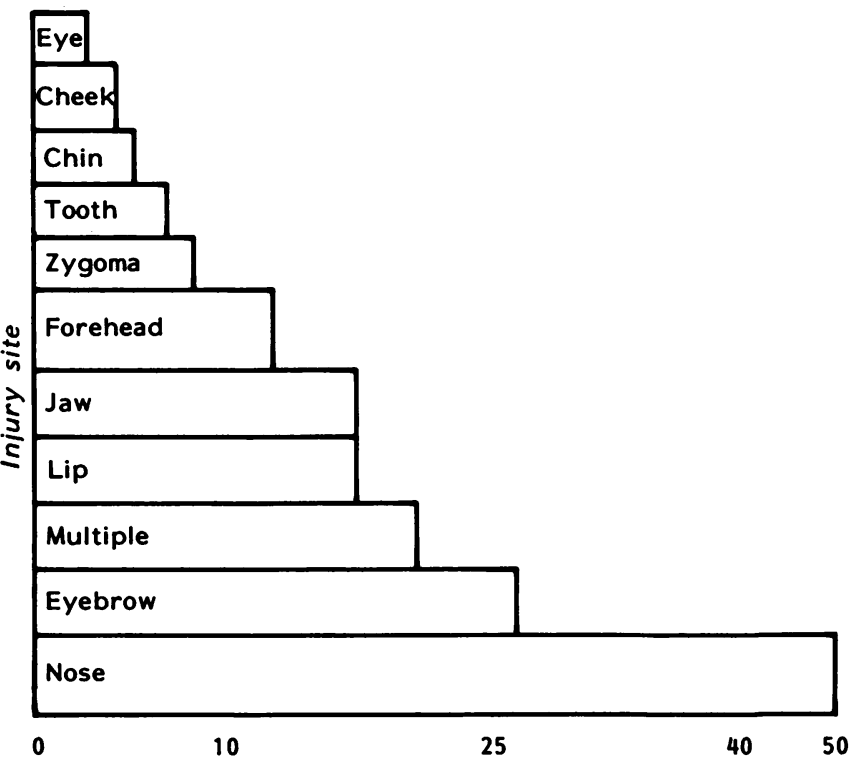

Figure 6. Face injuries affecting 180 (22 per cent) players

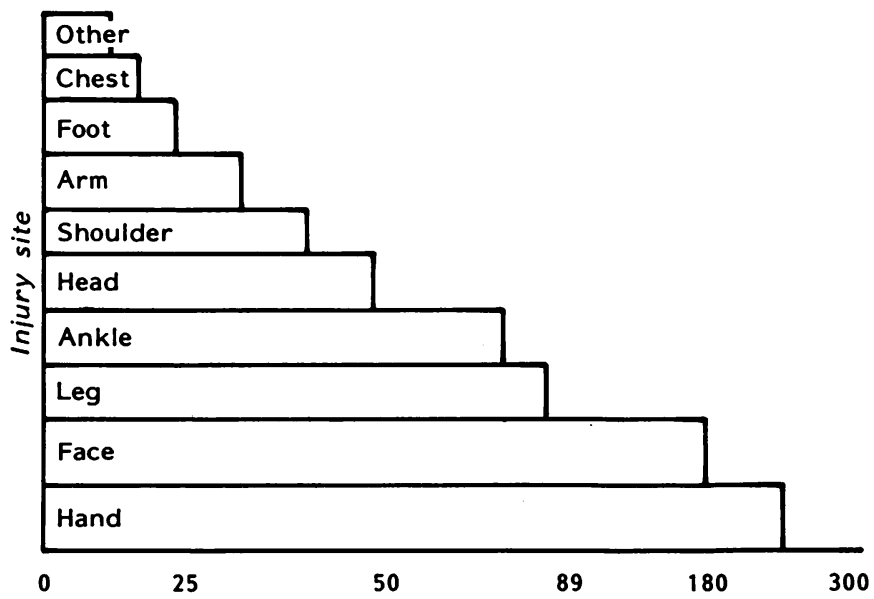

Figure 7. Injury sites

data to suggest that injuries in particular sites were dependent on the month of the year.

There were 107 sports injuries to the eye in a survey conducted in Cork's Eye, Ear and Throat Hospital between 1 January 1985 and 1 January 1986 by Dr P. Crowley and Mr P.E. Cleary, consultant opthalmic surgeon (Figure 8). Besides minor perio-orbital lacerations and sub-conjunctival haematomata, the majority of the other injuries listed in Figure 9 required admission to hospital for evaluation, observation and treatment as necessary.

\section{Discussion}

In all there were 817 injured players; 733 hurling players ( 90 per cent) and 84 ( 10 per cent) injured playing camogie. The numbers injured were highest for April, May and June. It is postulated that the reason for the decrease in numbers injured in May is due to the fact that this is an examination period when the 


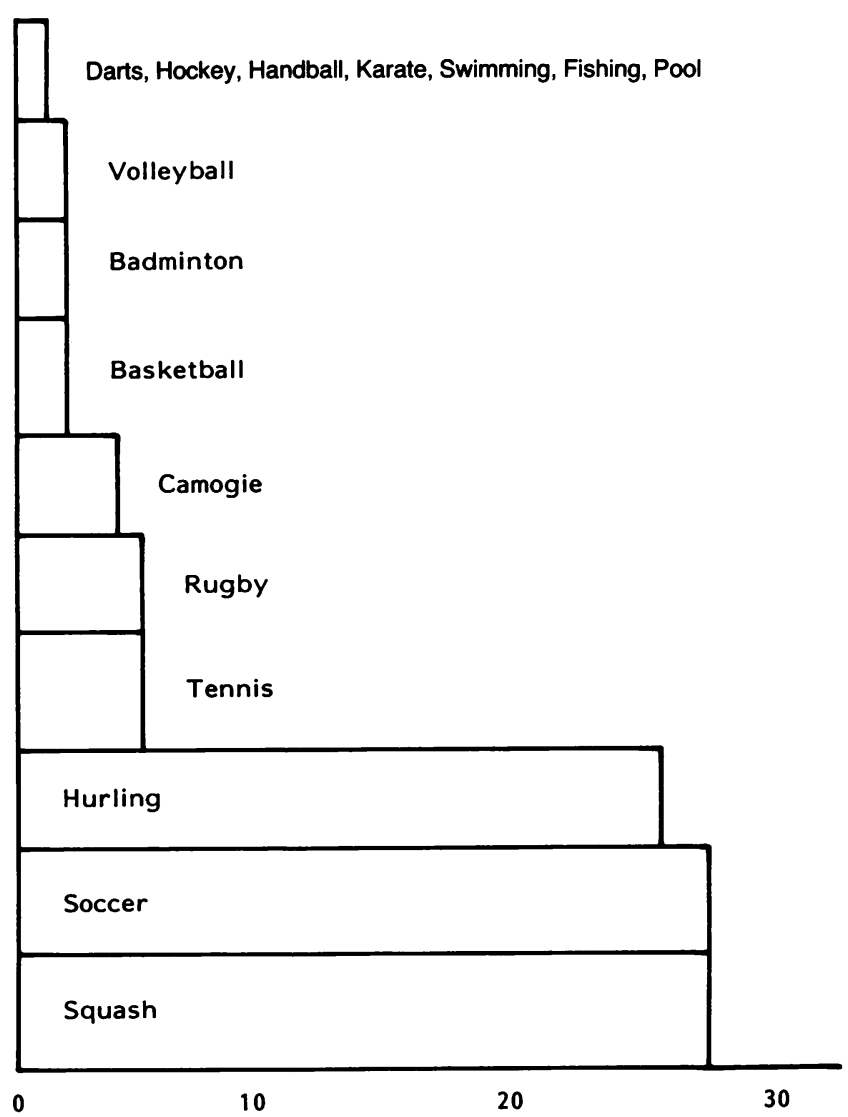

Figure 8. Injuries to the eye caused by various sports during one year at Cork Eye, Ear and Throat Hospital

number of matches is decreased in the under-age section. Figure 3 shows that 50 per cent of injury occurs in school attenders. Admission to hospital was required by 10 per cent, and one third of these required general anaesthetic.

The eye injuries correspond with previous reports ${ }^{1,2}$. A preventive face protection (Figure 10) has already been suggested ${ }^{1,3}$. It is hoped that this will reduce the injuries correspondingly, as occurred in icehockey ${ }^{4}$. Getting the players to wear protective headgear may be difficult, but it is our recommendation that it should be compulsory. It is hoped to show a significant reduction in injuries in patients wearing protective headgear in the future.

Hand injuries are the major problem and may prove more difficult to prevent. However, a good quality glove with reinforcement of particular areas should be considered.

\section{References}

1 Kelly, S. and Nolan, J. Eye injuries in organised sport in a rural area $\mathrm{Br} J$ Ophthalmol 1983, 67, 837-839

2 Cleary, P. and McAuliffe-Curtin, D. Eye injuries due to hurling Ir Med J 1982, 75(8), 289-290

3 O'Donoghue, J. and Condon, K.C. Facial injuries to hurlers. Ir Med Assoc 1979, 72(10), 448-449

4 Pashby. Eye injuries in Canadian ice hockey CMA Journal 1977, 117, 000-000

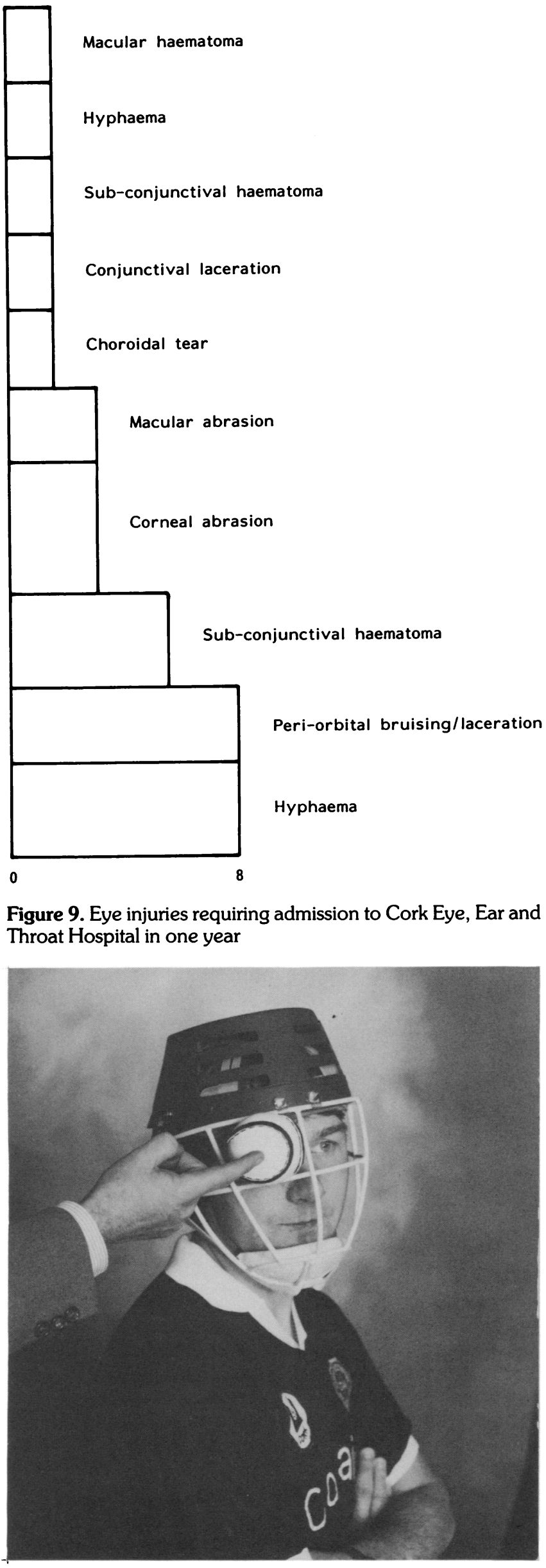

Figure 10. Protective headgear for hurling and camogie players 